\title{
Comunicação e educação: atualização da inteligência coletiva em salas de aula
}

\author{
Maria Ogécia Drigo* \\ Doutora em Comunicação e Semiótica pela Pontifícia Universidade Católica de São Paulo. \\ Mestra em Educação pela Universidade Metodista de Piracicaba. É docente do Programa de \\ Pós-Graduação em Comunicação e Cultura da Universidade de Sorocaba (UNISO). \\ E-mail: maria.drigo@uniso.br
}

Resumo: Na interface comunicação/educação, na qual se admite que o método de ensino/aprendizagem é um processo de comunicação, valer-se-á da cartografia antropológica e do conceito de inteligência coletiva desenvolvidas por Pierre Lévy. A intenção é conjeturar sobre a possibilidade de a semiótica de Charles Sanders Peirce contribuir para a compreensão dos processos de significação nos diversos espaços antropológicos e para explicitar a viabilização da atualização da inteligência coletiva em salas de aula.

Palavras-chave: comunicação, educação, semiótica, inteligência coletiva, práticas escolares.
Abstract: The purpose of this paper is to discuss about the possibility of Peirce's semiotics to contribute for understanding signification processes in different anthropological spaces and also to try to explain as to reach the actualization of collective intelligence in the classrooms. These reflections contemplate the interface communication/education, in which school teaching practices are looked as one process of communication, and the concepts of anthropological cartography and collective intelligence developed for Lévy.

Keywords: communication, education, semiotic, collective intelligence, teaching practices.

O propósito deste artigo é refletir sobre a contribuição da semiótica de Charles Sanders Peirce (1839-1914) para a compreensão de métodos de significação em diversos espaços antropológicos e, então, a partir de tal pressuposto, explicitar, em linhas gerais, como possibilitar a atualização da inteligência coletiva nos processos de ensino/aprendizagem.

Para atingir tal propósito, apresentamos, inicialmente, noções de espaços antropológicos e de inteligência coletiva desenvolvidas por Pierre Lévy; em seguida, discutimos a definição de signo para inventariar a pertinência da semiótica peirceana para o Espaço do Saber e concluímos com sugestões sobre a atualização da inteligência coletiva nas salas de aula.

Recebido: 17.03.2008

Aprovado: 11.08.2008

* Disponível em: <http:// lattes.cnpq.br/8349333 127597965>. 
1. $\mathrm{KUNSCH}, \mathrm{M} . \mathrm{M} . \mathrm{K}$. (Org.). Comunicação e educação: caminhos cruzados. São Paulo: Edições Loyola, 1986.

2. BRAGA, J. L.; CALAZANS, R. Comunicação e educação: questões delicadas na interface. São Paulo: Hacker Editores, 2001.

3. CITELLI, A. Comunicação e educação: a linguagem em movimento. São Paulo: Senac, 2000.

4. PFROMM NETTO, S. Telas que ensinam. Campinas: Editora Alínea, 2001.

5. ALAVA, S. et al. Ciberespaço e formações abertas: rumos a novas práticas educacionais? Porto Alegre: Artmed, 2002. p. 16 .

6. SANTAELLA, L.; NÖTH W. Comunicação e semiótica. São Paulo: Hacker Editores, 2004. p. 161

7. LÉVY, P. A inteligência coletiva. São Paulo: Edições Loyola, 2000. comunicação \& educação • Ano XIV • Número 2 • maio/ago 2009

A interface comunicação/educação é contemplada por estudiosos da comunicação. Kunsch ${ }^{1}$ relata o caminhar da Intercom no sentido de promover debates sobre tal interface. Braga e Calazans ${ }^{2}$ mencionam que uma das articulações mais evidentes dessa interface refere-se ao uso dos meios de comunicação nos processos formais de ensino, quer sejam presencial, quer a distância, sem deixar de considerar as consequências da proliferação do saber na sociedade, que pode ser atribuída também ao crescimento da presença dos meios de comunicação.

As investigações de Citelli ${ }^{3}$ adentram os ambientes escolares com o propósito de averiguar como os meios de comunicação incorporam novos elementos ao processo de ensino/aprendizagem. Também Pfromm $\mathrm{Netto}^{4}$, a partir da máxima telas que ensinam, explicita como a televisão, a internet e o cinema, entre outros meios, se tornam recursos para o ensino. O processo de ensino/aprendizagem envolve, portanto, não só aspectos da midiatização no contexto escolar, como o da mediatização. Não há comunicação que não seja mediatizada nem mesmo a nossa língua é expressão imediata do nosso pensamento ${ }^{5}$.

Nestas reflexões priorizamos o tratamento das disciplinas escolares como linguagens; logo, a mediatização será discutida no cruzamento de várias linguagens: a língua e a linguagem da disciplina escolar, principalmente.

A semiótica peirceana é um instrumental necessário para contemplar aspectos da mediatização nessa interface. Tal semiótica é considerada por investigadores, entre eles Santaella e Nöth, como uma teoria da comunicação.

Que a semiótica é também uma teoria da comunicação está implícito, em primeiro lugar, no fato de que não há comunicação sem signos. Em segundo lugar, está implícito no fato de que a semiose é, antes de tudo, um processo de interpretação, pois a ação do signo é a ação de ser interpretado em outro signo ${ }^{6}$.

Se um signo é interpretado por outro signo e assim sucessivamente, então, uma rede interpretativa se estabelece. Nos processos de ensino/aprendizagem tal rede deve ser consistente, ou seja, deve levar os sujeitos envolvidos a compartilhar significados.

A seguir, os espaços antropológicos e o conceito de inteligência coletiva.

\section{SOBRE A CARTOGRAFIA ANTROPOLÓGICA}

Pierre Lévy ${ }^{7}$ desenvolve uma cartografia antropológica a partir da hipótese de haver um novo espaço que emerge: o Espaço do Saber. As escalas utilizadas para atingir esse novo espaço são: terra, território e espaço das mercadorias.

Os espaços antropológicos são ambientes plásticos que vêm à tona pela interação das pessoas. Eles compreendem tanto as mensagens e as representações evocadas quanto essas mesmas pessoas que as possibilitam, bem como a situação como um todo, tal qual produzida e reproduzida pelos atos dos participantes. Os seres humanos não habitam apenas o espaço físico ou geométrico, mas também vivem em lugares afetivos, estéticos, sociais e históricos. Em qualquer dos espaços antropológicos, há produção de significados. 


\section{Comunicação e educação • Maria Ogécia Drigo}

Um espaço antropológico "é um sistema de proximidade (espaço) próprio do mundo humano (antropológico); portanto, depende de técnicas, de significações, da linguagem, da cultura, das convenções, das representações e das

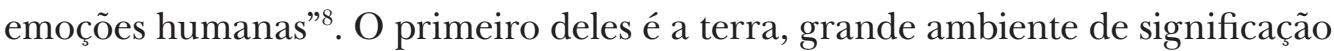
aberto à espécie humana, que repousa sobre as três características primordiais do homo sapiens: a linguagem, a técnica e as formas complexas de organização social. O segundo, o território, emergiu a partir do neolítico, com a agricultura, a cidade, o Estado e a escrita. Tal espaço não suprime a terra - domesticada e sedentarizada -, mas a recobre. O terceiro, o espaço das mercadorias, se desenvolveu desde o século XVI, com a inauguração de um mercado mundial por ocasião da conquista da América pelos europeus. O princípio organizador deste novo espaço é o fluxo: de energias, de matérias-primas, de mercadorias, de capitais, de mão de obra, de informações. Tal espaço não elimina os anteriores, porém, tem um ritmo diferenciado.

A terra "é esse espaço em que os homens, as pedras, os vegetais, os animais e os deuses se encontram, falam-se, fundem-se e separam-se para se reconstruir

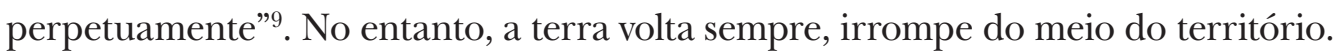

O espaço das mercadorias, ao adquirir autonomia em relação ao território, “[...] não abole simplesmente os espaços anteriores, mas sujeita-os, organiza-os segundo seus próprios objetivos. O velho território neolítico é estendido, mesclado, atravessado, furado, descosido, recoberto pelo tecnocosmo mercantil" ${ }^{\prime \prime}$.

Assim, tal espaço se espalha graças a essa máquina desterritorializante, que se organizou de uma só vez e a partir daí se (re)alimenta de tudo o que encontra, e transforma tudo em mercadoria. Que nova dimensão do ser humano nos auxiliaria a escapar dos percalços do espaço das mercadorias? Qual o cenário desse novo espaço que se desenha?

A novidade que se detecta - quer seja em pontos isolados, quer em faixas ou manchas - tem três aspectos:

[...] deve-se à velocidade de evolução dos saberes, à massa de pessoas convocadas a aprender e a produzir novos conhecimentos e, enfim, ao surgimento de novas ferramentas (as do ciberespaço) que podem fazer surgir, por trás do nevoeiro informacional, paisagens inéditas e distintas, identidades singulares, específicas desse espaço, novas figuras sócio-históricas ${ }^{11}$.

O mesmo autor acrescenta que a velocidade de evolução das ciências e das técnicas foi rápida e trouxe inúmeras consequências para a vida cotidiana. Assim, devido à grande quantidade de mensagens em circulação, necessitamos de filtros especiais para nos orientar, para que o coletivo humano se adapte, aprenda e invente, a fim de viver melhor. Nesse aspecto, qual seria a contribuição das novas ferramentas comunicacionais?

Seu uso mais útil, em termos sociais, seria sem dúvida fornecer aos grupos humanos instrumentos para reunir suas forças mentais, a fim de construir intelectuais ou "imaginantes coletivos". [...] O papel da informática e das técnicas de comunicação com base digital não seria "substituir o homem", nem se aproximar de

8. Ibid., p. 22

9. LÉVY, A inteligência coletiva, cit., p. 118

10. lbid., p. 115.

11. Ibid., p. 24 
uma hipotética "inteligência artificial", mas promover a construção de coletivos inteligentes, nos quais as potencialidades sociais e cognitivas de cada um poderão desenvolver-se e ampliar-se de maneira recíproca ${ }^{12}$.

Entretanto, onde está tal espaço que enfatiza a construção de intelectuais coletivos? O espaço do saber é habitado, animado por intelectuais coletivos imaginantes coletivos -, que sempre se estão reconfigurando. Ele está presente, mas de modo dissimulado, disperso, mesclado e ainda se encontra submetido às exigências da competitividade e aos cálculos do capital, no que se refere ao espaço das mercadorias. Quanto ao espaço do território, ele depende da gestão burocrática do Estado e, na terra, ainda é absorvido nos mundos cerrados e nas mitologias arcaicas.

No entanto, o saber não é somente o conhecimento científico, o qual é recente, raro e limitado. Ele é o que qualifica o homo sapiens, fruto da organização ou reorganização do ser humano na sua relação consigo mesmo e com o outro, sendo este outro as coisas do cosmo.

O intelectual coletivo é uma espécie de movimento autônomo no espaço do saber, que flui com os conhecimentos e a capacidade de ensinar e de aprender de cada ser humano. O coletivo inteligente:

[...] não submete nem limita as inteligências individuais; pelo contrário, exalta-as, fá-las frutificar e abre-lhes novas potências. Esse sujeito transpessoal não se contenta em somar as inteligências individuais. Ele faz florescer uma forma de inteligência qualitativamente diferente, que vem se acrescentar às inteligências pessoais $[\ldots]^{13}$.

A inteligência coletiva "é uma inteligência distribuída por toda parte, incessantemente valorizada, coordenada em tempo real, que resulta de uma mobilização efetiva das competências" ${ }^{\text {" }}$. Ela é distribuída por toda parte, ao considerar que ninguém sabe tudo, que todos sabem alguma coisa e que todo o saber está na humanidade.

Quanto aos meios de comunicação, eles devem propiciar aos membros de uma comunidade a coordenação das suas interações no mesmo universo virtual de conhecimentos. Assim sendo, a inteligência poderá ser coordenada em tempo real. Por outro lado, faz-se necessário uma mobilização efetiva das competências dos sujeitos envolvidos. É essencial, portanto, identificá-las, reconhecê-las em toda sua diversidade.

Assim, precisamos aprender a nos conhecer para pensarmos juntos. Para a construção de uma inteligência coletiva ou de uma imaginação coletiva, devem ser encorajados, preferencialmente:

12. Ibid., p. 25

13. Ibid., p. 94.

14. Ibid., p. 28

[...] os instrumentos que favoreçam o desenvolvimento do laço social pelo aprendizado e pela troca do saber; os agenciamentos de comunicação capazes de escutar, integrar e restituir a diversidade, em vez daqueles que reproduzem a difusão midiática tradicional; os sistemas que visam o surgimento de seres autônomos, qualquer que seja a natureza dos sistemas (pedagógicos, artísticos etc.) e dos seres (indivíduos, grupos humanos, obras, seres artificiais); as engenharias semióticas 
que permitam explorar e valorizar, em benefício da maioria, os jazigos de dados, o capital de competências e a potência simbólica acumulada pela humanidade ${ }^{15}$.

A construção da inteligência coletiva é importante para que o espaço do saber continue a se espalhar, quer seja por pontos, quer por faixas ou manchas. Mas, ainda segundo Lévy, em cada um destes espaços - devido às especificidades dos processos de significação que neles ocorrem - uma semiótica se delineia. Assim, semiótica é sinônimo de processo de significação. Os processos de significação envolvem os signos e os intérpretes. O quanto as coisas se distanciam de suas representações é uma especificidade do processo de significação, e esta relação também depende da história de semiose do intérprete, ou seja, como o intérprete se movimenta nos espaços antropológicos dados.

Na terra, universo da significação como reino da potência e da presença, "o signo participa do ser, e o ser do signo" ". Assim, os signos e as situações estão vinculados. Eles são potências vivas. Contudo, no território esses vínculos se desfazem, pois os signos passam a representar as coisas, ou seja, eles tornam presentes as coisas ausentes. No espaço das mercadorias, as distâncias tendem a aumentar, devido à grande proliferação de signos. Tudo é multiplicado e transformado pela mídia - quadros e rostos, paisagens e músicas, ritos e espetáculos -, e, também, todos os tipos de acontecimentos são indefinidamente reproduzidos e difundidos fora do seu contexto. Essa mistura sígnica interfere em quaisquer linguagens, o que acarreta um aumento da complexidade dos processos de significação.

E seria possível recuperarmos, pelo menos em parte, o original? Haveria chances de, no espaço do saber, retomarmos o contato com a realidade de modo mais estreito? Sim, e caberia aos intelectuais coletivos a tarefa de reconstituir um plano de imanência da significação, no qual os seres, os signos e as coisas voltassem a encontrar uma relação dinâmica de participação recíproca, escapando às separações do território, assim como aos circuitos espetaculares da mercadoria.

Que semiótica seria adequada, então?

\section{UMA SEMIÓTICA...}

P. Lévy menciona que as engenharias semióticas permitiriam explorar e valorizar, em benefício da maioria, a potência simbólica acumulada pela humanidade, na construção da inteligência coletiva. A tarefa dessas engenharias seria aproximar o mundo dos signos e o das coisas, que, para o autor, se foram distanciando de um espaço antropológico a outro. Há uma ciência dos signos que trata dessa passagem, sem rupturas.

No interior das ciências da linguagem, várias disciplinas se ocupam da significação, tais como Semântica Discursiva, Hermenêutica, Análise do Discurso, Semiótica, entre outras. Todas elas elegem a significação da linguagem como foco de análise, com seus próprios métodos, instrumentos e quadros
15. LÉVY, P. As tecnologias da inteligência: o futuro do pensamento na era da informática. Rio de Janeiro: Ed. 34 1998. p. 110

16. Id. A inteligência coletiva, cit., p. 141. 
17. HARTSHORNE, C. et al. Collected Papers of Charles Sanders Peirce (Coletânea de Charles Sanders Peirce). Cambridge/Massachusetts: Harvard University Press, 1931-35 e 1958. CP 1.284 (CP indica Collected Papers; o primeiro número corresponde ao volume e o segundo, ao capítulo).

18. SANTAELLA, L. Estética de Platão a Peirce. São Paulo: Experimento, 1994. p. 158. metodológicos. No entanto, a semiótica peirceana é a que alcança os quesitos para ser o instrumental do espaço do saber. Não vamos tratar de toda a arquitetura filosófica de Peirce nestas reflexões, mas se nos reportarmos à definição de signo, devido à própria especificidade dessa arquitetura filosófica, podemos justificar tal pertinência.

Na semiótica peirceana, o conceito de signo abarca tanto a linguagem verbal como as não verbais; logo, contempla todos os tipos de signos, bem como misturas sígnicas. Ainda, a fenomenologia, que fundamenta a semiótica e as outras ideias peirceanas, é categoria do conhecimento. Segundo Peirce, fenômeno "é o total coletivo de tudo aquilo que está de qualquer modo presente na mente, sem qualquer consideração se isto corresponde a qualquer coisa real ou não"17; e há três modos pelos quais se constitui a nossa experiência, a saber: por meio da qualidade, da alteridade e da mediação. Estas três categorias fenomenológicas mostram o mundo como aparência, como realidade e o mundo cognoscível, respectivamente.

Mas sendo o acesso ao real sempre mediado, como é possível não nos perdermos neste amálgama de signos e nos distanciarmos da realidade... cada vez mais? Durante a semiose - ação do signo -, o objeto resiste em uma rede de significados (interpretantes), ou seja, a primazia real é do objeto. O signo é sempre parcial por representar, por substituir o objeto; então, ele tenta resgatar essa dívida para com o objeto, gerando interpretantes.

Peirce levou a noção de signo tão longe a ponto do seu interpretante, quer dizer, o efeito que o signo produz, não ter de ser necessariamente uma palavra, uma frase ou um pensamento, mas poder ser uma ação, reação, um mero gesto, um olhar, um calafrio de regozijo percorrendo o corpo, um desfalecimento, devaneios incertos e vagos, uma esperança, estado de desespero, enfim, qualquer reação que seja, ou até mesmo um estado de indefinição do sentimento que sequer possa receber o nome de reação ${ }^{18}$.

O interpretante seria uma outra representação relativa ao mesmo objeto. O interpretante de um signo é, portanto, outro signo. Mas, por sua vez, esse signo/interpretante gera como interpretante um outro signo/interpretante, e assim sucessiva e infinitamente.

O interpretante, quer seja o imediato, quer o dinâmico ou o final, será dividido em emocional, quando estiver vinculado ao sentimento; energético, quando ligado à reação, e lógico, quando unido ao significado. Portanto, como qualquer um deles pode prevalecer, a ação do signo permite vivenciar uma qualidade de sentimento, experienciar determinada conduta ou produzir controle crítico deliberado de hábitos e crenças.

Para nos movimentarmos no espaço de saber, a compreensão da definição triádica de signo - e o seu efeito como significação, o que lhe confere um caráter pragmático, no sentido peirceano - é fundamental. Assim, se algo afeta a mente e se faz signo, estamos também nos aproximando do real.

Entretanto, como o signo está no lugar do objeto, mas não é o objeto, há sempre brechas entre eles. Esse espaço é o que se alarga, se expande, se dife- 
rencia, com os interpretantes autogerados pelo signo. Assim, há espaço para o novo, o original emergir e, portanto, para que os signos cresçam e o cosmo se modifique, aumente, se estenda. O ser humano, para se localizar no espaço do saber, precisa vivenciar essas brechas, ser criativo. A noção de inteligência coletiva, tal como Lévy nos apresenta, nos leva a conjeturar que a atualização de tal inteligência depende de que os signos autogerados caminhem nessas brechas.

Por outro lado, a mente, como signos em ação, é virtual ${ }^{19}$. A mente humana é uma atualização da mente. Essa ideia nos conduz a vislumbrarmos a possibilidade de atualização da inteligência coletiva, uma vez que ela é virtual.

As ideias estão no cosmo e se atualizam, independentemente de estarmos conectados. Há uma teia de signos, uma rede de significados permeando o cosmo, e elas se propagam quer existam quer não máquinas para facilitar os seus movimentos. As tecnologias da inteligência e o conceito de inteligência coletiva auxiliam na compreensão de que é admissível a existência de um tecido construído pelos signos em ação, bem como da sua atualização.

Mas como a inteligência coletiva pode se atualizar nos processos de ensino/ aprendizagem?

\section{CONSIDERAÇÕES FINAIS}

Como proceder para instaurar a inteligência coletiva em ambientes escolares? Há necessidade de construir um espaço propício para suscitar aprendizagens, capaz de envolver a atualização da inteligência coletiva, a qual corresponde a uma espécie de rede de significados instaurada, em que os nós são formados pelas inteligências individuais. Essa tessitura é tanto mais consistente quanto maior for a potencialidade dos signos e a capacidade dos nós para desvelar interpretantes. Para que isso se consolide, fazem-se necessárias algumas ações, que comentaremos a seguir.

$\left.1^{a}\right)$ Lançar um olhar semiótico para as disciplinas escolares, considerando-as como linguagens, e atentar para o fato de que em cada uma delas prevalecem determinados tipos de signos. A matemática e a arte são linguagens predominantemente icônicas. O termo linguagem se refere às formas sociais de comunicação e de significação que incluem a linguagem verbal articulada, mas envolve também, por exemplo, a matemática, a arte, a linguagem do computador, a culinária, a dança. Não há pensamento ou formas de raciocínio que se organizem exclusivamente por meio de símbolos. As palavras, frases, livros e outros signos convencionais são símbolos. Outros tipos de signos intervêm e são essenciais à condução do pensamento e das linguagens. A mistura sígnica é parte integrante de todas as manifestações de linguagem. A semiótica peirceana trata de todos os tipos de signos, bem como da mistura deles; logo, pode ser pertinente para o estudo de quaisquer linguagens.

$\left.2^{\mathrm{a}}\right)$ Desenvolver atividades de aula contextualizadas para o ensino das disciplinas escolares. O contexto a que nos reportamos precisa resgatar mo-
19. A noção de mente, no sentido peirceano, como virtual e mente humana como atual atualização da mente -, é desenvolvida em: DRIGO, Maria Ogécia. Virtual/atual: mente/mente humana. Revista E-Compos, n. 9. Disponível em: <http:// www.compos.org.br/seer/ index.php/e-compos/article/viewFile/169/170>. Acesso em: 23 abr. 2009. 
comunicação \& educação • Ano XIV • Número 2 • maio/ago 2009

mentos de descoberta e de elaboração dos saberes, tanto na ciência como na arte. Assim, deve-se possibilitar que novos significados sejam incorporados aos assuntos apresentados e que, por sua vez, sejam compartilhados, em uma sala de aula, por exemplo. Logo, não devem ser apresentados como produtos prontos e acabados. Não podemos iniciar o ensino de um tópico por sua definição concluída, ou ensinar enumerando leis ou descrevendo e classificando objetos a partir de princípios não discutidos. Desse modo, o meio que as inteligências individuais percorrem se torna mais rico em significados, o que aumenta o potencial para significar no intérprete - coletivamente - e o potencial de significação dos signos. Por outro lado, há as diversas maneiras de construir esse contexto, e uma delas é a que se vale das tecnologias da inteligência.

$\left.3^{\mathrm{a}}\right)$ Utilizar as tecnologias da inteligência ${ }^{20}$ : computadores e internet. Elas se apresentam para modificar a natureza e a intensidade das relações entre os sujeitos e entre os sujeitos e as coisas. O computador amplia a mente humana, trazendo à tona com nitidez e alta velocidade atualizações de modelos que ela elabora de modo nebuloso e lento; faz simulações rapidamente e, de modo geral, dá cores e formas claras à imaginação. Também, ao se conectar em rede - internet -, em pouco tempo é possível obter muitas informações, dialogar com pessoas de diversas partes do planeta, sobre assuntos determinados, e em tempo real. Há, portanto, um aumento na velocidade das trocas, dos embates com o outro - o que faz com que o sujeito se torne mais suscetível aos signos em ação.

$\left.4^{a}\right)$ Enfatizar os tipos de raciocínio: dedução, indução e abdução, presentes tanto na ciência como na arte. Assim, para qualquer área do conhecimento, as atividades têm de primar pela atualização do tipo de raciocínio que nelas predomina; devem, se não forem pesquisas propriamente ditas - devido ao nível de escolaridade -, simular uma ação investigativa, na medida em que criam/(re) criam situações e momentos de descoberta já conhecidos, pelo menos de quem está orientando essa situação de ensino/aprendizagem. Ao utilizar o computador para algumas atividades que se valem de informações memorizadas, a mente humana está livre para que outros tipos de raciocínios se modernizem - como aquele que permite o desenvolvimento da criatividade.

O clima que se instaura ao envolver as inteligências individuais em tecidos significativos compartilhados - que modifica a potencialidade dos signos - possibilita a atualização da inteligência coletiva neste ambiente. Mas tal ambiente não tem fronteira fechada. São signos em ação que, como flashes, quanto mais intermitentes mais parecem contínuos. Por outro lado, o espaço permeado de signos em ação pode encontrar diferentes histórias de semioses, uma via para a efetiva comunicação, para o compartilhar de significados.

20. LÉVY, As tecnologias da inteligência..., cit.

\section{REFERÊNCIAS BIBLIOGRÁFICAS}

ALAVA, S. et al. Ciberespaço e formações abertas: rumos a novas práticas educacionais? Porto Alegre: Artmed, 2002.

BRAGA, J. L.; CALAZANS, R. Comunicação e educação: questões delicadas na interface. São Paulo: Hacker Editores, 2001. 


\section{Comunicação e educação • Maria Ogécia Drigo}

CITELLI, A. Comunicação e educação: a linguagem em movimento. São Paulo: Senac, 2000.

HARTSHORNE, C. et al. Collected Papers of Charles Sanders Peirce (Coletânea de Charles Sanders Peirce). Cambridge/Massachusetts: Harvard University Press, 1931-1935 e 1958. CP 1.284 (CP indica Collected Papers; o primeiro número corresponde ao volume e o segundo, ao capítulo.)

KUNSCH, M. M. K. (Org.). Comunicação e educação: caminhos cruzados. São Paulo: Edições Loyola, 1986.

LÉVY, P. As tecnologias da inteligência: o futuro do pensamento na era da informática. Rio de Janeiro: Ed. 34, 1998.

A inteligência coletiva. São Paulo: Edições Loyola, 2000.

PFROMM NETTO, S. Telas que ensinam. Campinas: Editora Alínea, 2001.

SANTAELLA, L. Estética de Platão a Peirce. São Paulo: Experimento, 1994.

SANTAELlA, L.; NÖTH, W. Comunicação e semiótica. São Paulo: Hacker Editores, 2004.

\section{Endereço eletrônico}

DRIGO, Maria Ogécia. Virtual/atual: mente/mente humana. Revista E-Compos, n. 9. Disponível em: <http://www.compos.org.br/seer/index.php/e-compos/ article/viewFile/169/170>. Acesso em: 23 abr. 2009. 


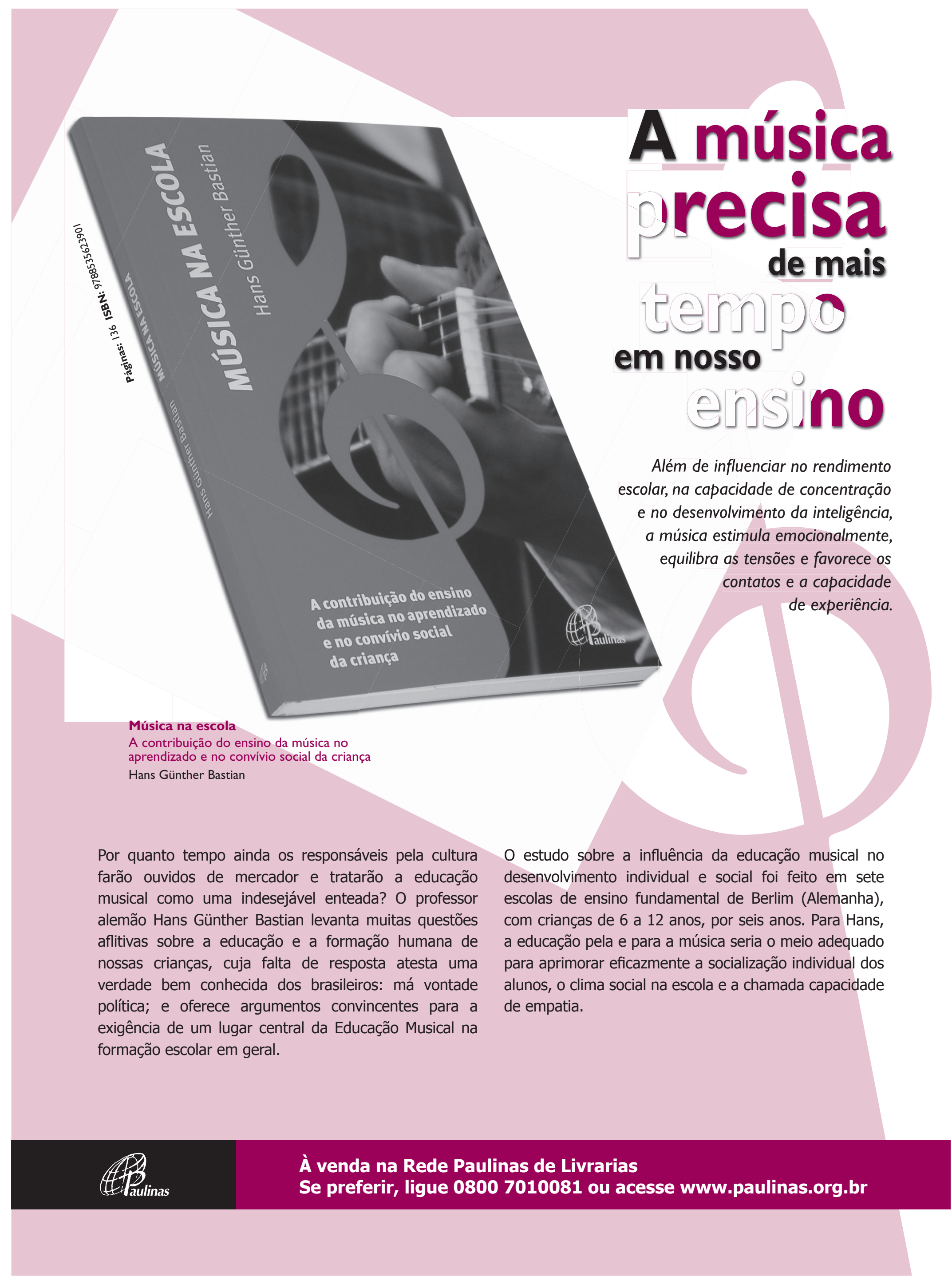

